non possit, tamen communitates earum partium id per literas testificantur patentes. Quod autem agere super hiis debeas, edoceri per sedem Apostolicam petiisti. Sane quia non est intentionis nostre, quod ultra sortem principalem quicquid a debitoribus predictis nisi expensas iustas et legittimas, si que propter culpam eorum facte fuerint, exigatur, discretioni tue per Apost. scripta mandamus in diesem Sinne vorzugehen, nachdem er den Sachverhalt festgestellt habe.

Karl Heinrich Schäfer in Rom.

\title{
„Die Darstellung Jesu im Tempel“ in der Pfarrkirche zu Schwarz- rheindorf.
}

In der Oberkirche $z u$ Schwarzrheindorf findet sich auf der Südwand des östlichen Kreuzarmes ein Gernälde der Aufopferung Jesu im Tempel, das von der herkömmlichen, an den Wortlaut des Evangeliums sich anschliessenden Darstellung erheblich abweicht. Eine befriedigende Erklärung der die Komposition bestimmenden Auffassung des biblischen Themas ist bis jetzt nicht gegeben worden ${ }^{1}$ ). Vielleicht vermögen die folgenden Bemerkungen etwas zum Verständnis des ungewöhnlichen Bildes beizutragen.

Eine deutliche Wiedergabe der uns beschäftigenden „Darstellung” Jesu" bietet aus'm Weerth' ${ }^{2}$ ). Der göttliche Heiland erscheint nicht als vierzigtägiges Kindlein auf den Armen seiner hl. Mutter, sondern er steht als etwa zehnjähriger Knabe beim Altare. Der hl. Joseph, der Vater Jesu vor dem Gesetze, ist im Begriffe, die sich faltenden Hände des Kindes mit dem Altare in Berührung zu bringen. Während Maria,

1) Ernst aus'm Weerth (Wandmalereien des christlichen Mittelalters in den Rheinlanden. 1880. S. 14 zu Taf. XXXIV) hebt die Abweichungen vom Evangelientexte hervor, ohne eine Erklärung derselben zu versuchen. H. J. Opfergelt (Die Doppelkirche zu Schwarz-Rheindorf. 1. Aufl. Bonn. S. 73) beschreibt das Bild in seiner von der biblischen Erzählung abweichenden Eigenart und fährt dann fort: „Man kann das Bild sich aber auch dahin erklären, dass Jesus eines Tages, abgesehen vom erwähnten Text, mit seinen Eitern in den jüdischen Tempel gekommen ist, um dem am Altare stehenden Priester eine Opfergabe darzubringen." Es wäre demnach an einen Vorwurf aus der apokryphen Evangelienliteratur zu denken. In der zweiten, bedeutend verkürzten Auflage des Büchleins (München 1907. S. 10) heisst es nur: „Auf der (dem Bilde des hl. Johannes Ev.) gegenüberliegenden Seite, ohne erkennbaren Zusammenhang mit dem Bisherigen, haben wir die Aufopferung Jesu im Tempel." Bei Pa ul Clemen (Die Kunstdenkmäler der Stadt und des Kreises Bonn, Düsseldorf 1905 S. 361) ist, der Anlage des Werkes entsprechend, das Bild nur seinem Inhalte nach erwähnt.

2) A. a. O. Taf. XXXIV. 2.

Annalen des hist. Vereins LXXXVl. 
in ihren Mantel gehüllt, die Szene verfolgt, tritt von der anderen Seite des Altares her Simeon mit feierlicher Würde dem Jesusknaben entgegen.

Irre ich nicht, so hat der Künstler ${ }^{1}$ ) hier die Darstellung Jesu im Tempel in den Formen des liturgischen und zugleich rechtssymbolischen Aktes der oblatio pueri veranschaulicht.

Über die Darbringung von Knaben in einem Kloster auf Lebenszeit verordnet der hl. Benedikt im 59. Kapitel seiner Regel, dass die Eltern die Bitte um Aufnahme stellen und die Hand des Kindes in das Altartuch wickeln sollen ${ }^{2}$ ). In seinem Kommentar zu dieser Stelle führt Martène folgende Beschreibung des Oblationsritus von Hildemar, einem Erklärer der Benediktinerregel im 9. Jahrhundert, an: Der Vater oder, wenn er gestorben ist, die Mutter soll sprechen: Ich N. N. lege vor Gott und seinen Heiligen an meines Sohnes Statt das Versprechen ab seines Verbleibens im Kloster (stabilitas), seines klösterlichen Lebens (conversio morum) und Gehorsams. Und er muss die Bitte um Aufnahme und das Versprechen schriftlich in seiner Hand halten an Stelle seines Sohnes. In die rechte Hand des Sohnes muss er eine Opfergabe mit einem Tuch legen, in die Linke ein Krüglein mit Wein. Darauf muss der Vater das Kind vor sich halten und dessen Hand in jenes Tuch wickeln ${ }^{3}$ ). Darauf muss er mit seiner Hand die in das Tuch gewickelte Hand des Sohmes und das Bittgesuch halten, und es müssen Zeugen zugegen sein. Alsdann muss der Abt ihn fragen: Was begehrst Du, Bruder? Jener muss antworten: Ich will meinen Sohn darbringen dem allmächtigen Gott $\mathrm{zu}$ seinem Dienste in diesem Kloster, weil Gott im Gesetze den Kin-

1) Vielleicht müssen wir sagen „die Künstlerin“. Opfergelt macht, m. E. mit Recht, auf die Möglichkeit aufmerksam (a.a. O. 1. Aufl. S. 74 f., 2. Aufl. S. 22), dass die Oberkirche - der Nonnenchor - von den Klosterfiauen selbst mit Gemälden geschmückt worden sei. Die Beobachtung, dass auch die männlichen, selbst die kriegerischen Heiligen (z. B. der hl. Florentius) einen weiblich zarten Charakter zeigen, ist wohl geeignet, diese Annahme noch zu unterstützen.

2) ${ }_{\text {Si }}$ quis de nobilibus offert filium suum Deo in monasterio, si ipse puer minori aetate est, parentes eius faciant petitionem et manum pueri involvant in palla altaris et sic eum offerant....... Similiter autem et pauperiores faciant. Qui vero ex toto nihil habent, simpliciter petitionem faciant et cum oblatione offerant filium suum coram testibus". Migne 66. $839 \mathrm{~s}$.

3) Dieser Deutung von „palla altaris“ der Benediktinerregel widersprechen andere Quellen. Erwähnt sei hier nur eine ebenfalls von Martène zitierte Stelle aus den Decreta Lanfranci pro ordine S. Benedicti (Kap. 17, Migne 150. 503): Qua oblatione a sacerdote suscepta, involvant praedicti parentes manus pueri in palla, qua altare coopertum est et cuius pars anterior pendet. Migne, a. a. 0.843 ; ebenda noch weitere Belege. 
dern Israels geboten hat, ihre Söhne Gott darzubringen, darum will ich diesen meinen Sohn in gleicher Weise Gott darbringen ${ }^{1}$.

Das Altartuch, die Opfergabe - etwa das im Evangelium erwähnte Taubenpaar - und die Urkunde (petitio) sind auf dem Wandgemälde nicht wahrzunehmen ${ }^{2}$ ). Dennoch scheint die eben angeführte Bestimmung der Benediktinerregel dem Maler vorgeschwebt zu haben. Berührt sie sich doch aufs engste mit dem dogmatischen Gedanken, der sich in der Aufopferung Jesu im Tempel ausspricht, und bezieht sich doch Hildemars Oblationsformel ausdrücklich auf das Vorbild im alten Bunde.

Ein anderer Umstand dürfte unserer Deutung des Bildes einen noch höheren Grad von Wahrscheinlichkeit sichern. Der Oblationsritus war nämlich auch bis ins spätere Mittelalter hinein ein Bestandteil der Consecratio virginum. So heisst es $z$. B. in einem Engelberger Pontificale Romanum aus dem 12. Jahrhundert ${ }^{3}$ ):

„Virginem episcopo parentes cum oblatione offerant et ille involutam manum eius in palla altaris recipiat dicendo cum astantibus antiphonam: Ipsi sum desponsata, cui angeli serviunt, cuius pulchritudinem sol et luna mirantur. ${ }^{4}$ )

Hier vollzieht sich also die Übergabe der Jungfrau aus der Gewalt des Vaters in die Munt des Bischofs bezw. der Kirche durch den Ritus der oblatio. Wenn man sich erinnert, dass Schwarzrheindorf ursprünglich ein Benediktinerinnenkloster war ${ }^{5}$ ), dessen Insassen einig'e

1) Ebda. $843 \mathrm{~s}$.

2) Wie in der Untexkirche, so wird auch in der Oberkirche die Ursprïnglichkeit der Malereien durch die Restauration beeinträchtigt worden sein. Vgl. W. v. Mirbach, Die ehemalige Stiftskirche zu Schwarzrheindorf bei Fr. Bock, Rheinlands Baudenlsmale des Mittelaltr.... Köln und Neuss. I. Serie. Dass das Altartuch wenigstens durc. , inige Linien angedeutet war, ist mehr als wahrscheinlich.

3) Cod. 54. fol. 85.

4) Die gleiche Rubrik findet sich in einem bei Martène (De antiquis ecclesiae ritibus, t. III. Antuerpiae 1763 p. 190 . ordo IV) abgedruckten Reimser Pontifikale. - Die den Tagzeiten der hl. Agnes (Breviarium Romanum: 21. Jan.) entlehnte Antiphon kann auch dem göttlichen Erlöser in den Mund gelegt werden, in dessen Person sich die menschliche Natur der göttlichen vermählt hat.

5) Der Kölner Erzbischof Philipp von Heinsberg sagt in einer tür Schwarzrheindorf ausgestellten Urkunde aus dem Jahre 1173: „Finem ergo, ad quem aspiraverat (seil. Hadewigis abbatissa Esnidensis), asse qui volens, in locum predictum duas sorores suas Sophiam et Siburgim devotas deo feminas induxit, quibus venerabilem sanctimonialium conventum adiunxit, qui una cum illis se ibidem humiliter includi pertulit et quatenus divina annueret gratia per omnia secundum regulam Benedicti deo militare elegit. " Lacomblet (Urkundenbuch für die Geschichte des Niederrheins. 1. Bd. Diisseldorf 1840. 
Zeit nach Ablegung ihrer Ordensgelübde alle, mit Ausnahme der Witwen, die Jungfrauenweihe erhielten, so wird man verstehen, dass die auf dem Lichtmessbilde dargestellte oblatio in bedeutsamer Beziehung zu den Nonnen stand, die den liturgischen Gottesdienst in der Oberkirche abhielten. Christus - $a \rho \chi\left(\pi \alpha \rho \theta \epsilon v \circ \zeta^{1}\right)$ - erscheint auf dem Gemälde als Vorbild der sich ihm weihenden Jungfrauen.

Beachtenswert ist auch, dass sich das Bild des Heilandes und der seligisten Jungfrau auf der Epistelseite befindet, während der hl. Johannes Ev. die Evangelienseite einnimmt. Der Oblationsakt vollzog sich eben mit der Darbringung der Opfergaben an der Epistelseite.

Sollten die vorstehenden Ausführung'en die Zustimmung der Kunsthistoriker finden, so dürfte das besprochene Gemälde in seiner Eigenart auch für die Beantwortung der schon berührten Frage von Bedeutung sein, ob nämlich die Oberkirche ihren Bilderschmuck kunst. begabten Nonnen verdankt.

$$
\text { P. Ildefons Herwegen O. S. B }
$$

\section{Zur Frage nach der Herkunft der Familie Gelenius.}

Johannes Gelenius $(* 1585, \dagger 1631)$, der Erforscher der Geschichte Kölns, Generalvikar unter Kurfürst Ferdinand, führte den Beinamen „a uf dem Herpis“. Bereits sein Urgrossvater muss sich um 1520 so genannt haben, denn auf einer im Jahre 1642 von Aegidius Gelevius, dem Verfasser des Buches „De magnitudine Coloniae“, eigenhändig niedergeschriebenen Stammtafel der Familie wird dieser Vorfahr „Martiuus Gelen condictus a uff Herpis" genannt.

Es ist mir bisher nicht gelungen, eine befriedigende Erlsli: *:iug für die Bezeichnung "auff Herpis" $z u$ finden.

Der Beiname kommt in verschiedenster Form vor. Ausser den bereits genannten Schreibarten fand ich: Herbes, in Herbis, a uf Herbes, auf Herpes, a uf dem Herbes, von Herpesch. Hartzheim (Bibl. Colon. p. 9) nennt als Vater des Aegidius Gelenius den "Henricus Gelenius ab Herpesch".

Im Kopulationsbuch von St. Brigitta in Cöln findet sich unter dem 29. September 1612 das Ehe-Aufgebot des „Michael auff Herbis

S. 311 n. 445). Heinrich Schäfer (Die Kanonissenstifter im deutschen Mittelalter. Heft 43 u. 44 der Kirchenrechtlichen Abhandlungen von U. Stutz. Stuttgart 1907. S. 21, Anm. 2) zweifelt, ob man in Schwarzrheindorf wirklich nach der Regel des hl. Benedikt oder als Kanonissen lebte. Vielleicht gibt unser von monastischen Riten inspiriertes Bild in idealer Weise Antwort zugunsten des regulären Lebens.

1) Methodius, Symposion, Logos I. c. V. Migne 18. 45 B. vgl. Hugo Koch, Virgines Christi. Leipzig 1907. S. 94. 